\title{
Clinical, biochemical and genetic spectrum of low alkaline phosphatase levels in adults
}

Leyre Riancho-Zarrabeitia ${ }^{1}$, Mayte García-Unzueta ${ }^{2}$, Jair A. Tenorio ${ }^{3}$, Juan A. GómezGerique $^{2}$, Víctor L. Ruiz Pérez ${ }^{4}$, Karen E. Heath ${ }^{3,5}$, Pablo Lapunzinaa ${ }^{3,5}$ and José A. Riancho ${ }^{6}$

1. Dept. of Rheumatology, Hospital Universitario Marqués Valdecilla, IDIVAL. Santander, Spain.

2. Dept. of Clinical Biochemistry, Hospital Universitario Marqués Valdecilla, IDIVAL. Santander, Spain.

3. Institute of Medical and Molecular Genetics (INGEMM), Hospital Universitario La Paz. IdiPAZ. Universidad Autónoma de Madrid and CIBERER, ISCIII. Madrid, Spain.

4. Instituto de Investigaciones Biomédicas “Alberto Sols", IdiPAZ, UAM-CIBERERISCIII, Madrid, Spain.

5. Skeletal Dysplasia Multidisciplinary Unit, Hospital Universitario La Paz, Madrid, Spain

6. Dept. of Internal Medicine. Hospital Universitario Marqués Valdecilla, IDIVAL, University of Cantabria, RETICEF, Santander, Spain.

leyre1987@hotmail.com

garciaunzueta@yahoo.es

jairantonio.tenorio@salud.madrid.org

jgomez@humv.es

v1ruiz@iib.uam.es

kheath71@yahoo.com

pablo.lapunzina@salud.madrid.org

rianchoj@unican.es

Correspondence:

Dr. José A. Riancho

Dept. of Internal Medicine

Hospital U. M. Valdecilla

Av Valdecilla sn.

39008 Santander, Spain

Fax +34 942201965

Tel +34942201990

Email rianchoj@unican.es

Running title: Hypophosphatasemia in adults 


\section{ABSTRACT}

Background: Low serum levels of alkaline phosphatase (ALP) are a hallmark of hypophosphatasia. However, the clinical significance and the underlying genetics of low ALP in unselected populations are unclear.

Methods: In order to clarify this issue, we performed a clinical, biochemical and genetic study of 42 individuals (age range 20-77 yr) with unexplained low ALP levels.

Results: Nine had mild hyperphosphatemia and three had mild hypercalcemia. ALP levels were inversely correlated with serum calcium $(\mathrm{r}=-0.38, \mathrm{p}=0.012)$, pyridoxal phosphate $(\mathrm{PLP} ; \mathrm{r}=-0.51, \mathrm{p}=0.001)$ and urine phosphoetenolamine $(\mathrm{PEA} ; \mathrm{r}=-0.49, \mathrm{p}=0.001)$. Although many subjects experienced minor complaints, such as mild musculoskeletal pain, none had major health problems. Mutations in $A L P L$ were found in 21 subjects (50\%), including six novel mutations. All but one, were heterozygous mutations. Missense mutations were the most common (present in 18 subjects; $86 \%$ ) and the majority were predicted to have a damaging effect on protein activity. The presence of a mutated allele was associated with tooth loss ( $48 \%$ versus $12 \%$; $=0.04)$, slightly lower levels of serum ALP $(\mathrm{p}=0.002)$, higher levels of PLP $(\mathrm{p}<0.0001)$ and PEA $(\mathrm{p}<0.0001)$, as well as mildly increased serum phosphate $(\mathrm{p}=0.03)$. Ten individuals (24\%) had PLP levels above the reference range; all carried a mutated allele.

Conclusion: One-half of adult individuals with unexplained low serum ALP carried an ALPL mutation. Although the associated clinical manifestations are usually mild, in approximately $50 \%$ of the cases, enzyme activity is low enough to cause substrate accumulation and may predispose to defects in calcified tissues.

KEYWORDS: alkaline phosphatase; hypophosphatasia; mutation analysis; pyridoxal phosphate; phosphoethanolamine; $A L P L$. 


\section{INTRODUCTION}

The clinical significance of low serum levels of alkaline phosphatase (ALP) is unclear and consequently clinicians may not pay attention to them. In fact, low ALP may be an irrelevant finding or accompany various systemic disorders $(1 ; 2)$. However, in some cases low ALP levels are the consequence of an underlying genetic disorder, hypophosphatasia, which influences tissue homeostasis, as well as drug responses.

Hypophosphatasia is a rare skeletal disorder due to a genetic defect in $A L P L$, the gene encoding the tissue-nonspecific (liver/bone/kidney) isoenzyme of ALP (3-5) or TNSALP. TNSALP is a homodimeric enzyme, with each monomer consisting of 524 amino acids. It connects to the cell membrane and functions as an ectophosphatase, hydrolyzing inorganic pyrophosphate (PPi), an inhibitor of mineralization, and other phosphate esters (6). Apart from TNSALP, the ALP family comprises of three tissue specific ALPs: intestinal, encoded by $A L P I$; placental, encoded by $A L P P$; and placental-like 2 or germ cell, encoded by ALPPL2 (7). ALPL consists of 12 exons, of which the first and part of the second are noncoding. Several forms of hypophosphatasia have been described, mainly in children $(6 ; 8)$, with considerable variations in the disease spectrum, even within the same family (9).

Low serum ALP activity is frequently the first finding leading to a suspicion of hypophosphatasia. The diagnosis may be confirmed by genetic testing or by measuring other phosphorylated substrates, such as pyridoxal-5'-phosphate (PLP) or phosphoethanolamine (PEA) (8). Hypophosphatasia in adults may either represent late manifestations of cases discovered in childhood, or adult onset forms (10-13). Cases with less severe manifestations may pass unrecognized. However, they may have important consequences, including an increased risk of adverse effects after taking medication frequently used for treating osteoporosis, i.e. bisphosphonates (14). On the other hand, the significance of lone low serum levels of ALP is unclear. Therefore, the aim of this study was to get a better understanding of 
the spectrum of low ALP levels in adults, by the active search of cases and the clinical, biochemical and genetic characterization of subjects with reduced serum ALP activity.

\section{MATERIALS AND METHODS}

\section{Subjects}

We reviewed serum ALP measurements in individuals aged 18 years and older during a 30-month period, in the Clinical Biochemistry laboratory, Hospital University Marqués Valdecilla, a tertiary facility serving a population of about 350,000 in Northern Spain. The clinical records of individuals with consistently low levels of ALP (see details in Results) were reviewed to exclude secondary causes of low ALP levels (2). Thus, patients with renal failure, malnutrition or antiresorptive drugs, were excluded. Then, individuals with consistently low levels of ALP of unknown cause were contacted by telephone and offered to participate in the study. It included a clinical interview with a standard protocol, a physical examination and obtaining blood and urine samples for biochemical and genetic analyses. The study was approved by the Institutional Review Board and all participants gave informed written consent.

\section{Biochemical and genetic analyses}

ALP was measured by a colorimetric method in an Advia 2400 analyzer (Siemens Healthcare, Munich, Germany). The reference range in adults is 40-129 U/1. Serum calcium and phosphorus were also measured in an Advia 2400 analyzer (Arsenazo III and Phosphomolybdate methods, respectively). Following manufacturer's instructions. The reference ranges were $8.1-10.4 \mathrm{mg} / \mathrm{dl}$ and $2.3-4.0 \mathrm{mg} / \mathrm{dl}$, respectively. The bone isoenzyme of alkaline phosphatase (BAP) was measured by enzymoimmunoassay (Microvue BAP EIA kit, Quidel Corporation, San Diego, CA, USA); with a reference range of 12-43 U/l. PEA and 
PLP were measured at Reference laboratory (Barcelona, Spain). Urinary PEA was measured by HPLC (derivatization with o-phthalaldehyde and reverse phase high performamnce liquid chromatography with fluorescence detection); normal levels are below $70 \mu \mathrm{mol} / \mathrm{g}$ creatinine. PLP was determined by an enzymatic assay (VB6 enzymatic PoBühlmann, Bühlmann Laboratories AG, Switzerland); the reference range was 23-173 nmol/l.

The screening of the coding sequences and intron/exon boundaries of $A L P L$ (NM_000478.4) was performed by direct sequencing. Primers were designed with the help of Primer 3 v0.4.0 software (http://bioinfo.ut.ee/primer3-0.4.0/) and SNPCheck V3 (https://secure.ngrl.org.uk/SNPCheck/snpcheck.htm) (Table 1). PCR products were sequenced using the BrightDye Terminator cycle kit (Nimagen, Nijmegen, The Netherlands) and run on an ABI3730XL Sequencer (Applied Biosystems, Foster City, CA). Conservation, in silico pathogenicity prediction and control population frequency analysis (ExoAC, Exome aggregation consortium) of the identified $A L P L$ variants was carried out using Alamut V2.6-1 software (Interactive Biosoftware, Rouen, France) and MutPred (http://mutpred.mutdb.org/) and the evolutionary criteria proposed by Silvent et al (7).We also consulted the ALPL mutation database (http://www.sesep.uvsq.fr/03_hypo_mutations.php) to check if any detected variant had been previously described, supporting its pathogenicity. We adopted the recommendations and guidelines of the American College of Medical Genetics and Genomics (15).

\section{Statistical analysis}

Comparisons between groups were analyzed by Mann-Whitney U tests or $\mathrm{Chi}^{2}$ tests, as indicated. The correlation between biochemical parameters was estimated as the Spearman's correlation coefficient. All tests were 2-tailed and p-values less than 0.05 were considered as statistically significant. 


\section{RESULTS}

After searching the laboratory database ( $n=\sim 500,000$ ALP analyses), we identified 12,546 serum ALP determinations in 8,758 patients below the lower limit of the reference range (40 U/1). A more stringent $26 \mathrm{U} / \mathrm{l}$ threshold was chosen hereafter to increase specificity and avoid including individuals with occasional values below the standard normal range, likely to lack biological relevance. In 466 blood tests, performed in 181 patients, the enzyme level was <26 U/l. Among them, 130 individuals had persistently low levels (defined for the purpose of this study as at least one test result $<26 \mathrm{U} / 1$ and none $>40 \mathrm{U} / 1$ prior to the current study). After reviewing the clinical records, unexplained persistently low levels were found in 50 individuals. Of these, 42 unrelated subjects (10 men, 32 women) with an age range of 2077 years (mean 50, median 49) were willing to participate in the study. A physician interviewed them and blood and urine samples were obtained for analysis.

Many subjects were asymptomatic or had mild ailments. A total of 24 complained of mild skeletal or muscular pain; 12 had suffered fractures (most were related to trauma and could not be necessarily considered due to bone fragility); two had a history of periarthritis and/or tendinopathy; nine had a diagnosis of osteoarthritis; nine, hypertension; one, coronary heart disease; and 13 had lost one or more teeth in the absence of trauma before 40 years of age.

Total ALP levels were positively correlated with BAP, and negatively with serum calcium $(r=-0.38, p=0.01)$, serum PLP $(r=-0.51, p=0.001)$, and urine PEA $(r=-0.49, p=0.001)$ (table 2, Fig. 1). Serum PLP correlated with serum phosphorus $(r=0.49, p=0.001)$ and urinary PEA $(r=0.58, p<0.001)$, and negatively with BAP $(r=-0.54, p<0.001)$. Urinary PEA levels were within the reference range in all but one subject. Nine patients had mild 
hyperphosphatemia, whereas three had serum calcium levels slightly above the upper reference limit (Fig. 2).

ALPL mutations were found in 21/42 subjects (20 heterozygotes and 1 homozygote), including nine previously published (16-23) and six unreported mutations (Table 3). Most mutations were observed in single patients. However, the substitution p.(Thr166Ile) was present in three patients, whereas two other changes, p.(Ser181Leu) and p.(Thr148Ile), were each present in two subjects. Eighteen patients (86\%) had a missense mutation; two had frameshift mutations; and one had a splice site mutation. The majority of the mutations were located in exons 5 and 6 (12 amino acids mutated in 17 patients), all of which were predicted to have a damaging effect on protein activity using bioinformatics algorithms and were absent or at extremely low frequency in control populations (Table 3).

The presence of a mutated allele was associated with early tooth loss (48\% vs. $12 \%$; $\mathrm{p}=0.04)$, slightly lower ALP ( $30 \pm 6$ vs. $25 \pm 6 \mathrm{u} / \mathrm{l} ; \mathrm{p}=0.002)$, higher levels of enzyme substrates, such as serum PLP $(p<0.0001)$ and urine PEA $(p<0.0001)$, and serum phosphate $(p=0.03)$ (Fig.2). Ten patients had PLP levels above the normal range, all of whom carried a gene mutation. The patient with the c.352C>A [p.Leu118Met);(Leu118Met)] homozygous mutation did not show obvious clinical differences to those with heterozygous mutations (she only had mild bone pain and low alkaline phosphatase levels). The variant was predicted to be pathogenic in 2/4 in silico analysis and absent from all control population databases. Thus, this variant is a variant of unknown significance.

\section{DISCUSSION}

Hypophosphatasia is a rare disorder with a prevalence of the severe form between 0.31/100,000 (8). Less severe forms, as those observed in adults, may be considerably more frequent, up to 1/6,000 in European populations (24). In a recent study, persistent 
hypophosphatasemia was found in 1/1,544 adult patients seen at a multispeciality health clinic (25). A low ALP level is frequently the first clue pointing to hypophosphatasia. However, it may also have secondary non-genetic causes, such as therapy with anti-resorptive drugs, renal failure-associated adynamic bone disease, celiac disease, hypothyroidism, multiple myeloma, etc. $(1 ; 2 ; 14 ; 25)$. Also, serum ALP may transiently decrease in severe acute diseases (2), probably reflecting the inhibition of osteoblast activity accompanying the stress response (26). In the present series, we found that $50 \%$ of adults with repeatedly low ALP levels had a mutation in $A L P L$. All mutations were predicted to impair the enzyme activity. In fact, haploinsufficiency was enough to reduce serum ALP activity, and in about one-half of the cases with mutations there was biochemical evidence of accumulation of phosphorylated substrates, such as PLP. About 285 loss of function ALPL mutations have been described to date; most of them missense mutations (3), as it was also observed in the present study. A French reference laboratory suggested that the mutation c.571G>A (p.Glu191Lys) may be particularly frequent in European cases with mild forms (3), but this mutation was absent in our cohort. However, we detected eight mutations that had not been previously reported. In our series, mutations tended to accumulate in exons 5 and 6 . This could be due to the fact those exons encode highly conserved sequences (96\% and $98 \%$ across species, respectively (7)), involved in several functionally important domains, including the homodimeric interface and active sites. Hence, even heterozygous mutations could have an effect on enzyme activity. No mutation was identified in 21 individuals with low ALP levels. These might either represent the lower extreme of the normal distribution, or be carriers of a mutation in an intron or regulatory region of $A L P L$. Whatever the explanation, all individuals with a normal genetic study had normal levels of PLP and PEA. Therefore, the remaining enzyme activity appeared to be enough to avoid the accumulation of ALP substrates. 
In practice, the diagnosis of hypophosphatasia is usually established by the combination of suggestive clinical manifestations, low ALP, and high levels of serum PLP or urinary PEA (8). However, PLP seems to have much higher sensitivity than PEA $(6 ; 8)$. In fact, only one individual in this series had PEA levels above the reference range, yet several had markedly increased PLP. There was no close association between serum PLP and ALP, but all individuals with high PLP levels had a mutated allele. Therefore, in the absence of genetic data, PLP seems to be a good diagnostic marker.

Perinatal and infantile hypophosphatasia are autosomal recessive diseases. The milder forms may be inherited in a recessive or dominant manner $(3 ; 23 ; 27)$. Heterozygotes who are carriers of a recessive mutation may be asymptomatic or have mild symptoms. However, the spectrum of this disorder is broad-ranging, even within members of the same family sharing the same mutation (9). Skeletal problems described in adult patients with hypophosphatasia include abnormalities of the bone, joint and soft-tissues, such as osteomalacia, low-bone mass and microarchitectural abnormalities, chondrocalcinosis, osteoarthritis, periarthritis, premature loss of teeth, myopathy, enthesopathy, etc. (11-13).

A few patients in our analysis exhibited some of these abnormalities; tooth loss being the most common, but many had no obvious skeletal problems. It is unclear to what extent some mild symptoms, such as aches and pains were related to low ALP activity or just incidental findings. On the other hand, the majority of our patients were relatively young (7/42 were $>65$ years), and it is unclear whether they will suffer hypophosphatasia-associated skeletal problems with aging. Also, since we did not perform routine imaging studies, some skeletal abnormalities may have gone unnoticed. In a recent report of 22 patients with symptomatic hypophosphatasia diagnosed in adulthood, the median age at symptom onset was 44 yr. Muscular pain and fractures were the most common manifestations. Interestingly, only $9 \%$ of patients had a positive family history (13). 
Overall, our results suggest that most adult individuals with low ALP levels, even those with confirmed gene mutations and deficient ALP activity, are asymptomatic or have only mild manifestations. Yet, it is important to identify this disorder. Even in the absence of specific clinical manifestations, individuals with ALP deficiency may be at risk of developing adverse effects when they are prescribed antiresorptive drugs, such as bisphosphonates. The occurrence of atypical femoral fractures, although rare, is an adverse effect of these drugs that has been increasingly recognized in recent years (28-30). Bisphosphonates are analogues of PPi that suppress bone turnover but also might deactivate ALP (14). The pathogenesis of atypical fractures is unclear, but it may be related to the inhibition of bone turnover and the accumulation of non-healing microfractures. Although most patients with atypical fractures do not have evidence of $A L P L$ mutations (31), individuals with low ALP activity may be at increased risk. In fact, patients with hypophosphatasia and bisphosphonate-related atypical fractures have been reported (14). Likewise, prescribing bisphosphonates to patients with low ALP activity and renal insufficiency may be particularly risky (32). Thus, at minimum a determination of serum PLP should be obtained in individuals with persistently low ALP levels, even in the absence of specific complains. If PLP is increased, a genetic analysis may be considered.

In conclusion, $50 \%$ of adult individuals with persistent low levels of serum ALP had a mutation in ALPL. Although clinical manifestations are usually mild, in about $50 \%$ of cases the enzymatic activity is low enough to cause the accumulation of phosphorylated substrates. These individuals might be classified as having an occult, oligosymptomatic form of hypophosphatasia. This diagnosis should be carefully considered in any individual with unexplained low levels of ALP, especially if treatment with antiresorptive agents is to be started. In the absence of genetic data, serum PLP is the best confirmatory test. 


\section{LEARNING POINTS}

- Most patients with unexplained low levels of alkaline phosphatase are asymptomatic or have minor musculoskeletal complains or biochemical abnormalities of mineral metabolism.

- About one half of them carry a mutation in the coding region of the ALPL gene, usually in heterozygous state. Of these, about one half have evidence of reduced enzyme activity enough to cause substrate accumulation.

- In the absence of genetic testing, serum pyridoxal phosphate (PLP) has higher sensitivity for diagnosis than other parameters, such as urinary phosphoethanolamine.

- Patients with reduced alkaline phosphatase might be at increased risk of complications if treated with anti-resorptive drugs such as bisphosphonates.

\section{ACKNOWLEDGEMENTS:}

This work was supported by an unrestricted grant from Alexion. The funding source had no role in study design or data analysis.

\section{DISCLOSURES:}

PL and JAR have received research grants from Alexion.

All authors declare that they do not have any other conflicts of interest. 


\section{Reference List}

(1) Lum G. Significance of low serum alkaline phosphatase activity in a predominantly adult male population. Clinical Chemistry 1995; 41(4):515-518.

(2) McKiernan FE, Shrestha LK, Berg RL, Fuehrer J. Acute hypophosphatasemia. Osteoporos Int 2014; 25(2):519-523.

(3) Mornet E. Genetics of hypophosphatasia. Clin Rev Bone Miner Metab 2013; 11:7177.

(4) Whyte MP. Enzyme defects and the skeleton. In: Rosen CJ, editor. Primer on the metabolic bone diseaes and disorders of mineral metabolism. Ames: Wiley-Blackwell, 2014: 838-842.

(5) Whyte MP. Hypophosphatasia: Nature's window on alkaline phosphatase in humans. In: Bilezikian JP, Raisz LG, Martin TJ, editors. Principles of bone biology. San Diego: Academic Press, 2008: 1573-1598.

(6) Whyte MP. Physiological role of alkaline phosphatase explored in hypophosphatasia. Ann N Y Acad Sci 2010; 1192:190-200.

(7) Silvent J, Gasse B, Mornet E, Sire JY. Molecular evolution of the tissue-nonspecific alkaline phosphatase allows prediction and validation of missense mutations responsible for hypophosphatasia. J Biol Chem 2014; 289(35):24168-24179.

(8) Hofmann C, Girschick HJ, Mentrup B, Graser S, Seefried L, Liese J et al. Clinical aspects of hypophosphatasia:an update. Clin Rev Bone Miner Metab 2013; 11:60-70.

(9) Hofmann C, Girschick H, Mornet E, Schneider D, Jakob F, Mentrup B. Unexpected high intrafamilial phenotypic variability observed in hypophosphatasia. Eur J Hum Genet 2014; 22:1160-1164.

(10) Baujat G, Cormier-Daire V, Le Merrer M. Hypophosphatasia: the disease in adults. Clin Rev Bone Miner Metab 2013; 11:78-83.

(11) Guanabens N, Mumm S, Moller I, Gonzalez-Roca E, Peris P, Demertzis JL et al. Calcific periarthritis as the only clinical manifestation of hypophosphatasia in middleaged sisters. J Bone Miner Res 2014; 29(4):929-934.

(12) Barvencik F, Beil FT, Gebauer M, Busse B, Koehne T, Seitz S et al. Skeletal mineralization defects in adult hypophosphatasia--a clinical and histological analysis. Osteoporos Int 2011; 22(10):2667-2675.

(13) Berkseth KE, Tebben PJ, Drake MT, Hefferan TE, Jewison DE, Wermers RA. Clinical spectrum of hypophosphatasia diagnosed in adults. Bone 2013; 54(1):21-27.

(14) Sutton RA, Mumm S, Coburn SP, Ericson KL, Whyte MP. "Atypical femoral fractures" during bisphosphonate exposure in adult hypophosphatasia. J Bone Miner Res 2012; 27(5):987-994. 
(15) Richards S, Aziz N, Bale S, Bick D, Das S, Gastier-Foster J et al. Standards and guidelines for the interpretation of sequence variants: a joint consensus recommendation of the American College of Medical Genetics and Genomics and the Association for Molecular Pathology. Genet Med 2015; 17:405-424.

(16) Witters I, Moerman P, Mornet E, Fryns JP. Positive maternal serum triple test screening in severe early onset hypophosphatasia. Prenat Diagn 2004; 24(7):494-497.

(17) Mumm S, Jones J, Finnegan P, Henthorn PS, Podgornik MN, Whyte MP. Denaturing gradient gel electrophoresis analysis of the tissue nonspecific alkaline phosphatase isoenzyme gene in hypophosphatasia. Mol Genet Metab 2002; 75(2):143-153.

(18) Ozono K, Yamagata M, Michigami T, Nakajima S, Sakai N, Cai G et al. Identification of novel missense mutations (Phe310Leu and Gly439Arg) in a neonatal case of hypophosphatasia. J Clin Endocrinol Metab 1996; 81(12):4458-4461.

(19) Taillandier A, Lia-Baldini AS, Mouchard M, Robin B, Muller F, Simon-Bouy B et al. Twelve novel mutations in the tissue-nonspecific alkaline phosphatase gene (ALPL) in patients with various forms of hypophosphatasia. Hum Mutat 2001; 18(1):83-84.

(20) Spentchian M, Merrien Y, Herasse M, Dobbie Z, Glaser D, Holder SE et al. Severe hypophosphatasia: characterization of fifteen novel mutations in the ALPL gene. Hum Mutat 2003; 22(1):105-106.

(21) Mornet E, Taillandier A, Peyramaure S, Kaper F, Muller F, Brenner R et al. Identification of fifteen novel mutations in the tissue-nonspecific alkaline phosphatase (TNSALP) gene in European patients with severe hypophosphatasia. Eur J Hum Genet 1998; 6(4):308-314.

(22) Taillandier A, Zurutuza L, Muller F, Simon-Bouy B, Serre JL, Bird L et al. Characterization of eleven novel mutations (M45L, R119H, 544delG, G145V, H154Y, C184Y, D289V, 862+5A, 1172delC, R411X, E459K) in the tissue-nonspecific alkaline phosphatase (TNSALP) gene in patients with severe hypophosphatasia. Mutations in brief no. 217. Online. Hum Mutat 1999; 13(2):171-172.

(23) Lia-Baldini AS, Muller F, Taillandier A, Gibrat JF, Mouchard M, Robin B et al. A molecular approach to dominance in hypophosphatasia. Hum Genet 2001; 109(1):99108.

(24) Mornet E, Yvard A, Taillandier A, Fauvert D, Simon-Bouy B. A molecular-based estimation of the prevalence of hypophosphatasia in the European population. Ann Hum Genet 2011; 75(3):439-445.

(25) McKiernan FE, Berg RL, Fuehrer J. Clinical and radiographic findings in adults with persistent hypophosphatasemia. J Bone Miner Res 2014; 29(7):1651-1660.

(26) Napal J, Amado JA, Riancho JA, Olmos JA, Gonzalez-Macias J. Stress decreases the serum level of osteocalcin. Bone Miner 1993; 21:113-118.

(27) Fauvert D, Brun-Heath I, Lia-Baldini AS, Bellazi L, Taillandier A, Serre JL et al. Mild forms of hypophosphatasia mostly result from dominant negative effect of severe 
alleles or from compound heterozygosity for severe and moderate alleles. BMC Med Genet 2009; 10:51.

(28) Edwards BJ, Bunta AD, Lane J, Odvina C, Rao DS, Raisch DW et al. Bisphosphonates and nonhealing femoral fractures: analysis of the FDA Adverse Event Reporting System (FAERS) and international safety efforts: a systematic review from the Research on Adverse Drug Events And Reports (RADAR) project. J Bone Joint Surg 2013; 95(4):297-307.

(29) Ettinger B, Burr DB, Ritchie RO. Proposed pathogenesis for atypical femoral fractures: lessons from materials research. Bone 2013; 55(2):495-500.

(30) Shane E, Burr D, Abrahamsen B, Adler RA, Brown TD, Cheung AM et al. Atypical subtrochanteric and diaphyseal femoral fractures: second report of a task force of the american society for bone and mineral research. J Bone Miner Res 2014; 29(1):1-23.

(31) Perez-Nunez I, Perez-Castrillon JL, Zarrabeitia MT, Garcia-Ibarbia C, Martinez-Calvo L, Olmos JM et al. Exon array analysis reveals genetic heterogeneity in atypical femoral fractures. A pilot study. Mol Cell Biochem 2015.

(32) Cundy T, Michigami T, Tachikawa K, Dray M, Collins JF, Paschalis EP et al. Reversible Deterioration in Hypophosphatasia Caused by Renal Failure With Bisphosphonate Treatment. J Bone Miner Res 2015; 30(9):1726-1737.

Correspondence:

Dr. José A. Riancho

Dept. of Internal Medicine

Hospital U. M. Valdecilla

Av Valdecilla sn.

39008 Santander, Spain

Fax +34 942201965

Tel +34942201990

Email rianchoj@unican.es 


\section{FIGURE LEGENDS}

Figure 1. Correlations between alkaline phosphatase (ALP) activity, bone alkaline phosphatase (BAP) and the substrate levels (pridoxal-5'-phosphate [PLP] and urinary phosphoethanolamine [PEA]) in 42 adults with low serum ALP.

Figure 2. Biochemical data of the 42 subjects. Alkaline phosphatase (ALP), calcium (Ca), phosphorus $(\mathrm{P})$, bone alkaline phosphatase (BAP), urinary phosphoethanolamine (PEA) and pyridoxal-5'-phosphate (PLP) in individuals with ALP activity and either an ALPL mutation (black circles, $n=21$ ) or no mutation (open circles, $n=21$ ). The dotted lines mark the limits of the reference ranges. 
Table 1. Primers sequences and amplicon sizes of the analysed ALPL exons.

\begin{tabular}{|c|c|c|c|}
\hline $\begin{array}{c}A L P L \\
\text { exon }\end{array}$ & Forward $\left(5^{\prime}>3^{\prime}\right)$ & Reverse $\left(5^{\prime}>3^{\prime}\right)$ & $\begin{array}{c}\text { Amplicon } \\
\text { size (bp) }\end{array}$ \\
\hline 2 & TCAGTTAACATCTGACCACTGC & CCСТCATCATACCCCATCTG & 215 \\
\hline 3 & CACCTCCAAGTTCAGGCATT & AAACACCСТTCCТCCAGAGC & 352 \\
\hline 4 & TACAGAGCCATGCCCAGTG & CTCTGGCTGCTGTCATGTTC & 326 \\
\hline 5 & AGTCCCCATGGTGTGAGTGT & AAGCCTTTTCTAGCCCСТTC & 357 \\
\hline 6 & AGGAGGCCTCTGGGACAC & GAGCCCATGGAGGAAAGATT & 364 \\
\hline 7 & AAGTGTCCACACCATCTCCAG & GAGCCCATGGAGGAAAGATT & 382 \\
\hline 8 & GATAGCTGCTGGGGTCAGTC & CTAAGTGGGCGTCAGGCTA & 247 \\
\hline 9 & CCAGCCACCATACTCTACCC & ACCCCCAAACCAGTCAGTTC & 366 \\
\hline 10 & TGGTGCTAGCTCAGAGTGGT & TGTCATTGAGTCCCCACCAT & 449 \\
\hline 11 & AAGCCACCAAGGAGCCTAAT & GCTGACACCCTATTCCCAAG & 280 \\
\hline 12 & CCTGGAAGGGAGATGGAAA & TGTGGGAAGTTGGCATCTGT & 399 \\
\hline
\end{tabular}


Table 2. Spearman's coefficients and p-values of correlations between several serum parameters and urine PEA.

\begin{tabular}{lccccc}
\hline & ALP & Calcium & Phosphorus & BAP & PEA \\
\hline Calcium & $\mathrm{r}=-0.382$ & & & & \\
& $\mathrm{p}=0.012$ & & & & \\
Phosphorus & $\mathrm{r}=-0.089$ & $\mathrm{r}=0.178$ & & & \\
& $\mathrm{p}=0.573$ & $\mathrm{p}=0.258$ & & & \\
BAP & $\mathrm{r}=0.519$ & $\mathrm{r}=-0.269$ & $\mathrm{r}=-0.196$ & & \\
& $\mathrm{p}<0.001$ & $\mathrm{p}=0.085$ & $\mathrm{p}=0.213$ & & \\
PEA & $\mathrm{r}=-0.487$ & $\mathrm{r}=0.406$ & $\mathrm{r}=0.503$ & $\mathrm{r}=-0.490$ & \\
& $\mathrm{p}=0.001$ & $\mathrm{p}=0.008$ & $\mathrm{p}=0.001$ & $\mathrm{p}=0.001$ & \\
& & & & & $\mathrm{r}=0.678$ \\
PLP & $\mathrm{r}=-0.513$ & $\mathrm{r}=0.223$ & $\mathrm{r}=0.494$ & $\mathrm{r}=-0.538$ & $\mathrm{p}$ \\
& $\mathrm{p}=0.001$ & $\mathrm{p}=0.155$ & $\mathrm{p}=0.001$ & $\mathrm{p}<0.001$ & $\mathrm{p}<0.001$ \\
\hline
\end{tabular}

ALP: total alkaline phosphatase

BAP: bone alkaline phosphatase

PEA: urinary phosphoethanolamine

PLP: pyridoxal-5'-phosphate 
Table 3. List of identified ALPL mutations and their in silico analysis.

\begin{tabular}{|c|c|c|c|c|c|c|c|c|c|c|}
\hline $\begin{array}{c}\text { HPP } \\
\mathbf{N}^{\mathbf{0}}\end{array}$ & $\begin{array}{l}\text { ALPL } \\
\text { Exon }\end{array}$ & $\begin{array}{c}\text { Mutation } \\
\text { (cDNA) }\end{array}$ & $\begin{array}{c}\text { Mutation } \\
\text { (Amino acid) }\end{array}$ & Polyphen2 & SIFT & MutationTaster & MutPred & Conservation & $\begin{array}{c}\text { Frequency } \\
\text { (ExoAC) }\end{array}$ & Reference \\
\hline HPP4 & 5 & c. $334 \mathrm{G}>\mathrm{A}$ & p.(Gly112Ser) & $\begin{array}{c}\text { Prob } \\
\text { damaging } \\
(1.00)\end{array}$ & $\begin{array}{l}\text { Tolerated } \\
(0.25)\end{array}$ & $\begin{array}{c}\mathrm{DC} \\
(1.00)\end{array}$ & $\begin{array}{c}\mathrm{DC} \\
(0.865)\end{array}$ & Yes & - & $\begin{array}{l}\text { Witters et } \\
\text { al, } 2004\end{array}$ \\
\hline HPP5 & 5 & c. $382 \mathrm{G}>\mathrm{A}$ & p.(Val128Met) & $\begin{array}{c}\text { Prob } \\
\text { damaging } \\
(0.993)\end{array}$ & $\begin{array}{l}\text { Damaging } \\
\quad(0)\end{array}$ & $\begin{array}{c}\mathrm{DC} \\
(1.00)\end{array}$ & $\begin{array}{c}\mathrm{DC} \\
(0.927)\end{array}$ & $\mathrm{CP}$ & - & $\begin{array}{l}\text { Mumm et } \\
\text { al, } 2002\end{array}$ \\
\hline HPP7 & 12 & c.1366G>A & p.(Gly456Arg) & $\begin{array}{c}\text { Prob } \\
\text { damaging } \\
(1.00)\end{array}$ & $\begin{array}{l}\text { Damaging } \\
(0)\end{array}$ & $\begin{array}{c}\mathrm{DC} \\
(1.00)\end{array}$ & $\begin{array}{c}\mathrm{DC} \\
(0.988)\end{array}$ & Yes & - & $\begin{array}{l}\text { Ozono et } \\
\text { al, } 1996\end{array}$ \\
\hline $\begin{array}{l}\text { HPP10 } \\
\text { HPP31 } \\
\text { HPP41 } \\
\end{array}$ & 6 & c. $497 \mathrm{C}>\mathrm{T}$ & p.(Thr166Ile) & $\begin{array}{c}\text { Prob } \\
\text { damaging } \\
(1.00)\end{array}$ & $\begin{array}{c}\text { Damaging } \\
\text { (0) }\end{array}$ & $\begin{array}{c}\mathrm{DC} \\
(1.00)\end{array}$ & $\begin{array}{c}\text { DC } \\
(0.797)\end{array}$ & Yes & - & - \\
\hline HPP15 & 5 & c. $334 \mathrm{G}>\mathrm{C}$ & p.(Glu112Arg) & $\begin{array}{c}\text { Prob } \\
\text { damaging } \\
(1.00)\end{array}$ & $\begin{array}{l}\text { Damaging } \\
(0.04)\end{array}$ & $\begin{array}{c}\mathrm{DC} \\
(1.00)\end{array}$ & $\begin{array}{c}\mathrm{DC} \\
(0.887)\end{array}$ & Yes & - & - \\
\hline $\begin{array}{l}\text { HPP18 } \\
\text { HPP34 }\end{array}$ & 6 & c. $542 \mathrm{C}>\mathrm{T}$ & p.(Ser181Leu) & $\begin{array}{c}\text { Poss } \\
\text { damaging } \\
(0.947)\end{array}$ & $\begin{array}{c}\text { Damaging } \\
(0.17)\end{array}$ & $\begin{array}{c}\mathrm{DC} \\
(0.982)\end{array}$ & $\begin{array}{c}\mathrm{DC} \\
(0.847)\end{array}$ & Yes & $\begin{array}{c}/ 66370 \\
\text { EA } \\
4 / 120868 \\
\text { ALL }\end{array}$ & $\begin{array}{c}\text { Lia- } \\
\text { Baldini et } \\
\text { al, } 2001\end{array}$ \\
\hline $\begin{array}{l}\text { HPP19 } \\
\text { HPP21 }\end{array}$ & 5 & c. $443 \mathrm{C}>\mathrm{T}$ & p.(Thr148Ile) & $\begin{array}{c}\text { Prob } \\
\text { damaging } \\
(0.994)\end{array}$ & $\begin{array}{c}\text { Tolerated } \\
(0.06)\end{array}$ & $\begin{array}{c}\mathrm{DC} \\
(1.00)\end{array}$ & $\begin{array}{c}\mathrm{DC} \\
(0.842)\end{array}$ & Yes & - & $\begin{array}{l}\text { Spentchian } \\
\text { et al, } 2003\end{array}$ \\
\hline HPP23 & 12 & c. $1417 \mathrm{G}>\mathrm{A}$ & p.(Gly473Ser) & $\begin{array}{c}\text { Prob } \\
\text { damaging } \\
(1.00)\end{array}$ & $\begin{array}{c}\text { Damaging } \\
(0.02)\end{array}$ & $\begin{array}{c}\mathrm{DC} \\
(1.00)\end{array}$ & $\begin{array}{c}\mathrm{DC} \\
(0.974)\end{array}$ & Yes & - & $\begin{array}{l}\text { Mornet et } \\
\text { al, } 1998\end{array}$ \\
\hline HPP24 & 10 & c.1083_1084dup & p.(Ser364Argfs*42) & - & - & - & - & - & - & - \\
\hline HPP26 & Int5 & c. $473-2 A>G$ & N/A & - & - & - & - & - & - & - \\
\hline HPP28 & 5 & c. $454 \mathrm{C}>\mathrm{T}$ & p.(Arg152Cys) & $\begin{array}{l}\text { Benign } \\
(0.072)\end{array}$ & $\begin{array}{c}\text { Damaging } \\
(0.03)\end{array}$ & $\begin{array}{c}\text { DC } \\
(0.992)\end{array}$ & - & $\mathrm{CP}$ & - & $\begin{array}{c}\text { Mornet et } \\
\text { al, } 2009\end{array}$ \\
\hline
\end{tabular}




\begin{tabular}{|c|c|c|c|c|c|c|c|c|c|c|}
\hline HPP29 & 5 & c. $407 \mathrm{G}>\mathrm{A}$ & p.(Arg136His) & $\begin{array}{c}\text { Prob } \\
\text { damaging } \\
(1.00)\end{array}$ & $\begin{array}{c}\text { Tolerated } \\
(0.12)\end{array}$ & $\begin{array}{c}\mathrm{DC} \\
(1.00)\end{array}$ & $\begin{array}{c}\text { DC } \\
(0.891)\end{array}$ & Yes & $\begin{array}{c}20 / 65972 \\
\text { EA } \\
24 / 120304 \\
\text { ALL } \\
\end{array}$ & $\begin{array}{l}\text { Taillandier } \\
\text { et al, } 1999\end{array}$ \\
\hline HPP33 & 5 & c. $358 \mathrm{G}>\mathrm{A}$ & p.(Gly120Arg) & $\begin{array}{c}\text { Prob } \\
\text { damaging } \\
(0.999)\end{array}$ & $\begin{array}{c}\text { Damaging } \\
(0)\end{array}$ & $\begin{array}{c}\mathrm{DC} \\
(1.00)\end{array}$ & $\begin{array}{c}\mathrm{DC} \\
(0.99)\end{array}$ & Yes & - & $\begin{array}{c}\text { Mornet et } \\
\text { al, } 1998\end{array}$ \\
\hline HPP35 & 5 & c. $352 \mathrm{C}>\mathrm{A} ; \mathrm{c} .352 \mathrm{C}>\mathrm{A}$ & p.(Leu118Met);(Leu118Met) & $\begin{array}{c}\mathrm{DC} \\
(1.00)\end{array}$ & $\begin{array}{c}\text { Tolerated } \\
(0.06)\end{array}$ & $\begin{array}{c}\mathrm{DC} \\
(1.00)\end{array}$ & $\begin{array}{l}\text { Neutral } \\
(0.577)\end{array}$ & Yes & - & - \\
\hline HPP36 & 9 & c. $871 \mathrm{G}>\mathrm{A}$ & p.Glu291Lys) & $\begin{array}{c}\mathrm{DC} \\
(1.00)\end{array}$ & $\begin{array}{c}\text { Damaging } \\
(0.38)\end{array}$ & $\begin{array}{c}\mathrm{DC} \\
(1.00)\end{array}$ & $\begin{array}{c}\mathrm{DC} \\
(0.874)\end{array}$ & Yes & - & $\begin{array}{c}\text { Mornet et } \\
\text { al, } 1998\end{array}$ \\
\hline HPP37 & 5 & c.383_384insG & p.(Val130Glyfs*6) & - & - & - & - & Yes & - & - \\
\hline HPP40 & 6 & c. $512 \mathrm{~A}>\mathrm{G}$ & p.(His171(Arg) & $\begin{array}{c}\mathrm{DC} \\
(1.00)\end{array}$ & $\begin{array}{c}\text { Damaging } \\
(0.04)\end{array}$ & $\begin{array}{c}\mathrm{DC} \\
(1.00)\end{array}$ & & Yes & $\begin{array}{c}0 / 66312 \\
\text { EA } \\
2 / 120810 \\
\text { ALL }\end{array}$ & $\begin{array}{c}\text { Mornet et } \\
\text { al, } 2001\end{array}$ \\
\hline
\end{tabular}

HPP $N^{o}$ represents our patient sample internal code, nucleotide nomenclature according to transcript NM_000478.4. Several predictors were applied to study the possible pathogenic effects of each mutation. Prob damaging (probably damaging, Poss damaging (Possibly damaging, DC, disease causing; B, benign;. Scores indicates the pathogenicity possibility of each mutation. Information about the Polyphen, SIFT, MutationTaster scores can be find on the user guide of Alamut V2.6-1 Software (http://www.interactive-biosoftware.com/) and MutPred scores at http://mutpred.mutdb.org/about.html. Species conservation according to Silvent et al (7), CP, conservative position (substitution conserving chemical properties). Population frequencys in ExoAC (EA: European American; ALL - all populations) 
Fig. 1
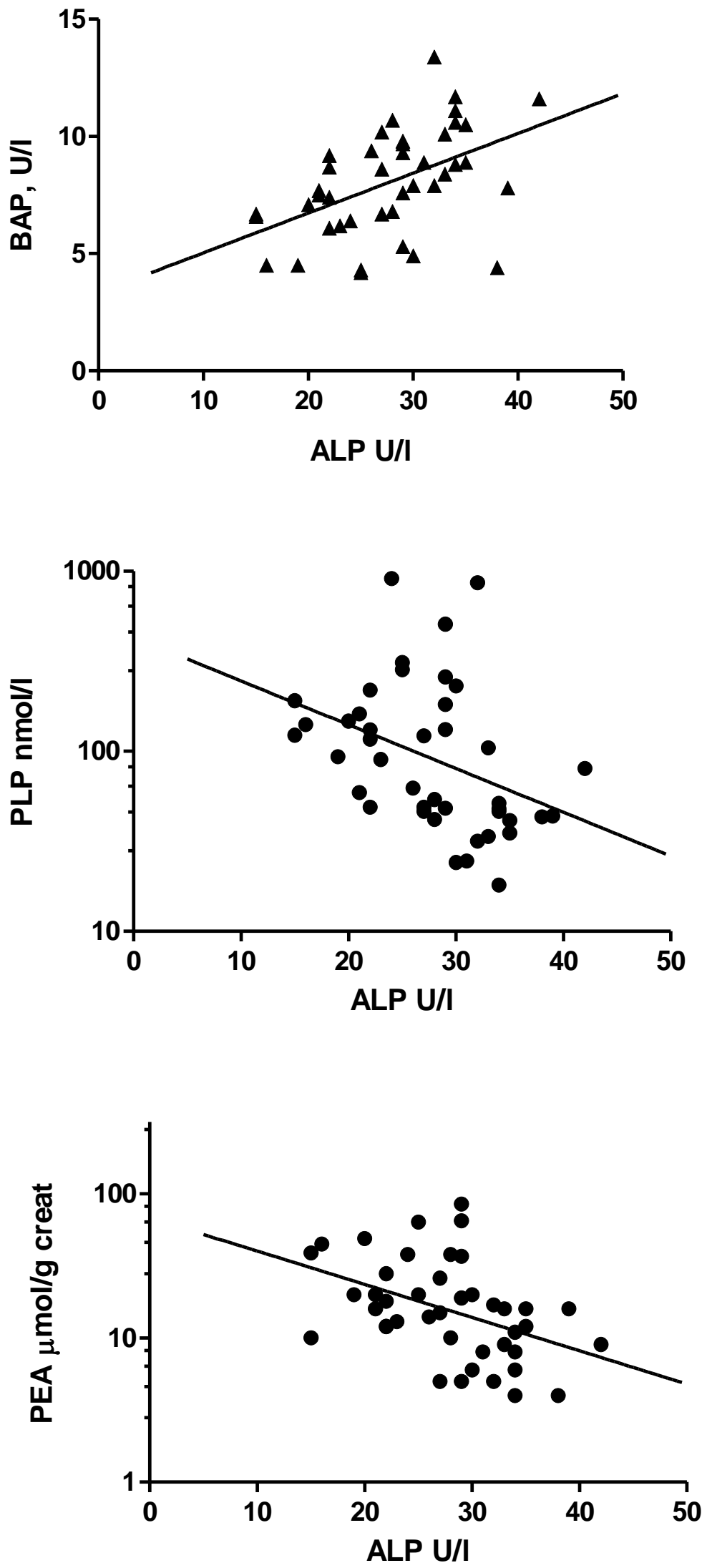
Fig. 2

ALP

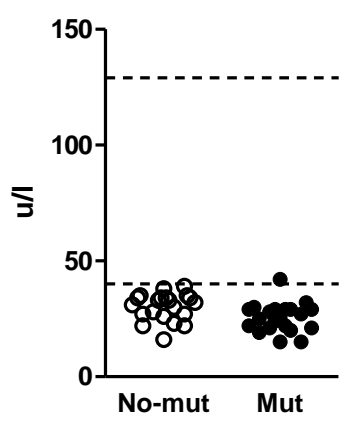

BAP

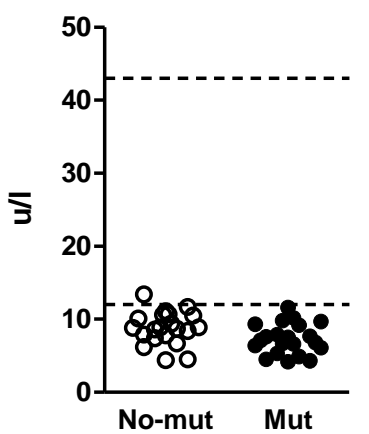

$\mathrm{Ca}$

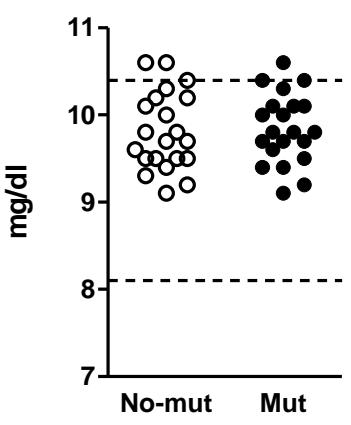

PEA

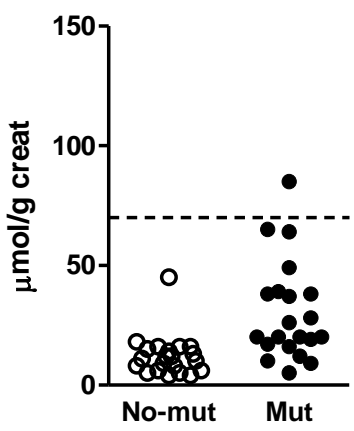

P

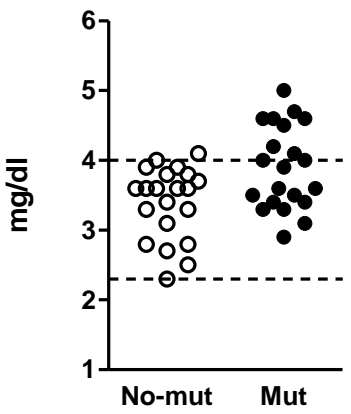

PLP

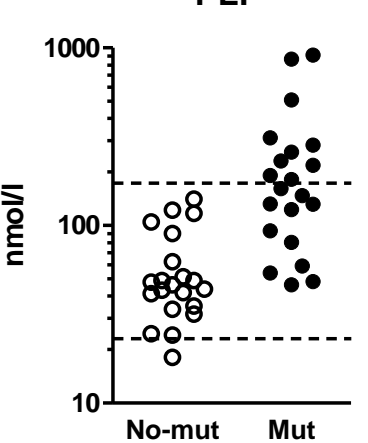

